\title{
Effects of early mobilization in reducing hospitalization time in critical patients in intensive care unit: an integrative literature review
}

\author{
Maria Hallana Souza Ribeiro'; Bruna Rafaela Dornelas de Andrade Lima Monteiro²; Palloma \\ Emanuelly Dornelas de Melo³; Sâmia Dayana Lemos de Lacerda*4
}

1 Graduated in Physiotherapy at UNIFACOL - University Center FACOL Faculdade Escritor Osman Lins, Vitória de Santo Antão, Pernambuco, Brazil.

2 Professor of the Physiotherapy course at UNIFACOL - University Center FACOL Faculty Writer Osman Lins, Vitória de Santo Antão, Pernambuco, Brazil.

3 Master's student of the Post-graduation program in Pharmaceutical Sciences (PPGCF) of the Federal University of Pernambuco (UFPE), Pernambuco, Brazil.

4 Professor of the Nursing course at UNIFACOL - University Center FACOL Faculty Writer Osman Lins, Vitória de Santo Antão, Pernambuco, Brazil.

E-mail adresses: mariahallana@outlook.com (Maria Hallana Souza Ribeiro), brunadornelasmonteiro@gmail.com (Bruna Rafaela Dornelas de Andrade Lima Monteiro), palloma_dornelas@hotmail.com (Palloma Emanuelly Dornelas de Melo), samia.lacerda@ufpe.br (Sâmia Dayana Lemos de Lacerda)

*Corresponding author

\section{To cite this article:}

Ribeiro, M.H.S.; Monteiro, B.R.D.A; Melo, P.E.D.; Lacerda, S.D.L. Effects of early mobilization in reducing hospitalization time in critical patients in intensive care unit: an integrative literature review. International Journal of Sciences. Vol. 2, No. 1, 2021, pp. 55-61. ISSN 2763-5392, DOI 000000000000000000

Received: 06 29, 2021; Accepted: 06 30, 2021; Published: 07 15, 2021

\begin{abstract}
The intensive care unit (ICU) is the place in the hospital designed to offer advanced life support and continuous care to sick patients with an imminent risk of death. Critical patients in the ICU may present some disorders due to immobility in the bed, resulting in muscle changes, cardiopulmonary complications and cognitive deficiencies. These factors can prolong the hospital stay of these patients, increasing the risk of complications and death. To analyze the effects of early mobilization in reducing the length of hospital stay in critically ill patients in the intensive care unit. It was an integrative literature review, with data obtained through research in the electronic databases: PubMed / MedLine, Scientific Electronic Library Online (Scielo), International Literature in Health Sciences (LILACS) and Google Scholar, in the months from August 2020 to June 2021, without language restrictions. Six articles were found that met the eligibility criteria, which were included in the integrative literature review. Through the results found, there was a decrease in the length of hospital stay of critical patients undergoing early intervention in the ICU, however, no significant differences were found between the groups. Further studies are needed to expand the evidence regarding the topic addressed.
\end{abstract}

Keywords: Early Ambulation; Intensive Care Units; Physiotherapy; Rehabilitation

\section{Introduction}

The intensive care unit (ICU) is the site in the hospital for the provision of advanced life support and continuous care to sick patients at imminent risk of death. It is formed by a multidisciplinary team composed of physicians, nurses, physiotherapists and occupational therapists, who work to minimize functional losses and recover these patients (CAVALCANTE. et al., 2018).
Critically ill ICU patients may present some disorders due to bed immobility, reflecting muscle changes, cardiopulmonary complications, and cognitive impairments. These factors can prolong the hospital stay of these patients, increasing the risk of complications and death (CAVALCANTE. et al., 2018; MOYER et al., 2017).

Most severe patients enter a picture of cardiorespiratory instability, and ventilatory support is necessary to maintain stability. However, mechanical ventilation is also considered a risk factor for the development of muscle weakness and 
polyneuropathy of the critical patient (FONSECA. et al., 2016).

Muscle weakness is one of the most common complications in icu patients, occurring due to electrolyte changes, systemic inflammations, sedation and nutritional deficiency, being aggravated by bed rest. Critically ill patient polyneuropathy is commonly associated with prolonged time in the ICU bed, characterized by vascular disorders, peripheral hyporeflexia, and especially muscle weakness. The severity of muscle weakness and its clinical manifestations can be prevented or reversed through early mobilization (CAVALCANTE. et al., 2018; Silva. et al., 2014).

Interventions that encourage mobility inside and outside the bed during hospitalization are essential to minimize functional losses and avoid prolonged hospitalization. It is recommended that these interventions be initiated as early as possible, through passive and active exercises listed from the patient's condition according to the evaluation (SCHUJMANN; LUNARDI; FU, 2018; Saints. et al., 2015).

Recent studies show benefits of early physiotherapy in the functionality of icu patients in the first 48 hours of mechanical ventilation (MV) establishment, but this intervention is still infrequent. In Brazil, $90 \%$ of critically ill patients are not mobilized beyond the bed (AQUIM. et al., 2019).

Early mobilization may be feasible and safe in critically ill patients, reducing the duration of mechanical ventilation and length of stay in the intensive care unit. In addition, to reduce delirium and mortality, thus improving the functionality of patient's post-hospital discharge (PIRESNETO. et al., 2015).

The members of the multidisciplinary team are responsible for evaluating the indications and contraindications in relation to early mobilization, but it is up to the physiotherapist to define the best method of intervention, time, intensity and duration. The main objective of the multidisciplinary team is to reduce the hospitalization time of these patients and promote functionality (AQUIM. et al., 2019).

Thus, the aim of this integrative literature review was to analyze the effects of early mobilization in reducing the time of hospitalization in critically ill patients in the intensive care unit.

\section{Methodology}

The present studywas based on an integrative review of the literature. Data were collected from August 2020 to June 2021 through electronic datab-ases: PubMed/MedLine, Scientific Electronic Library Online (Scielo), International Literature on Health Sciences (LILACS) and Google Scholar. The criteria for inclusion were: scientificrtigos on early mobilization,tortigos published between the years 2012 to 2021 , sin linguisticrestriction. The critérios of and xclusion were: monography, dissertations and doctoral theses,andstudocom neonates/children and duplicidade of articles in the databases. To search for the articles, the descriptors (DeCS) were used: early ambulation; intensive care units; physiotherapy; rehabilitation and descriptors (MeSH): early ambulation; intensive care units; physical therapy specialty; rehabilitation. Therefore, the titles and abstracts of the respective articles were read to confirm the association with the theme in question and its interventions. The complete texts were acquired for the critical analysis of the studies.

\section{Results and Discussions}

In the present study of integrative literature review, six articles that met the previously established inclusion criteria were analyzed. All selected according to the following flowchart.

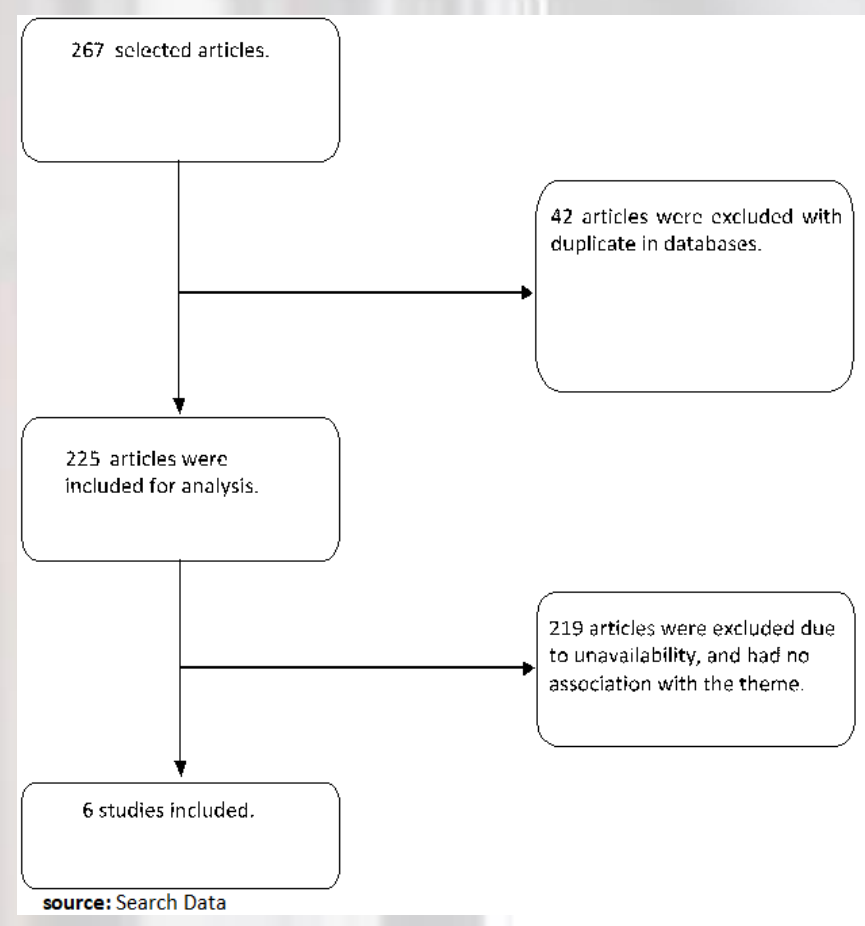

Figure 1. Strategic flowchart of selection of articles by databases

Among the selected articles, evidence was found that early mobilization is effective, contributes to the evolution of critically ill patients and decreases the time of hospitalization in the ICU (Chart $1)$.

Table 1. List of references that addressed the effects of early mobilization in reducing the time of hospitalization in critically ill patients in the intensive care unit, according to author, year, article title, study design, journal, sample size and results.

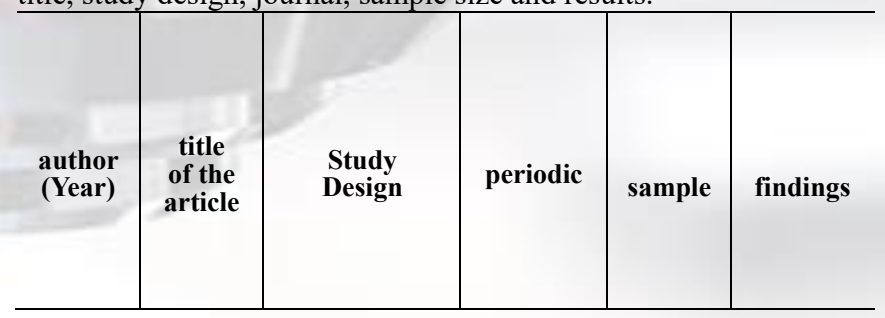




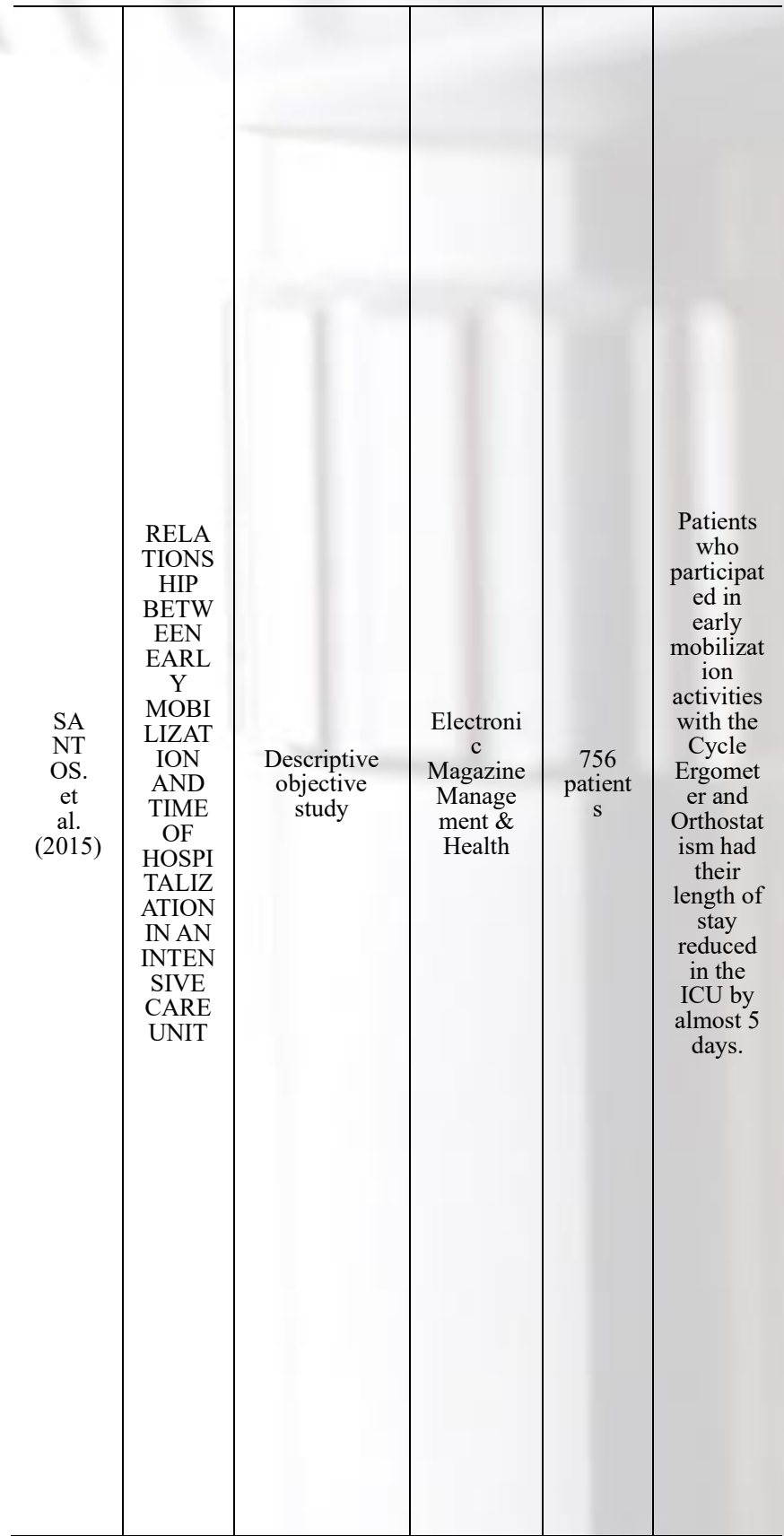

Source: Search Data

Table 2. List of references that addressed the effects of early mobilization in reducing the time of hospitalization in critically ill patients in the intensive care unit, according to author, year, article title, study design, journal, sample size and results.

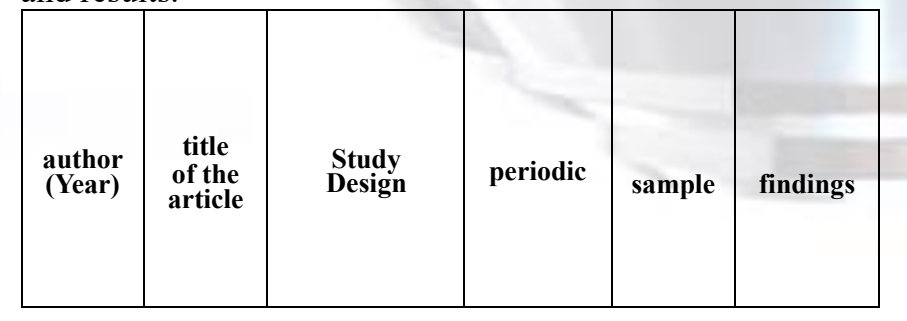

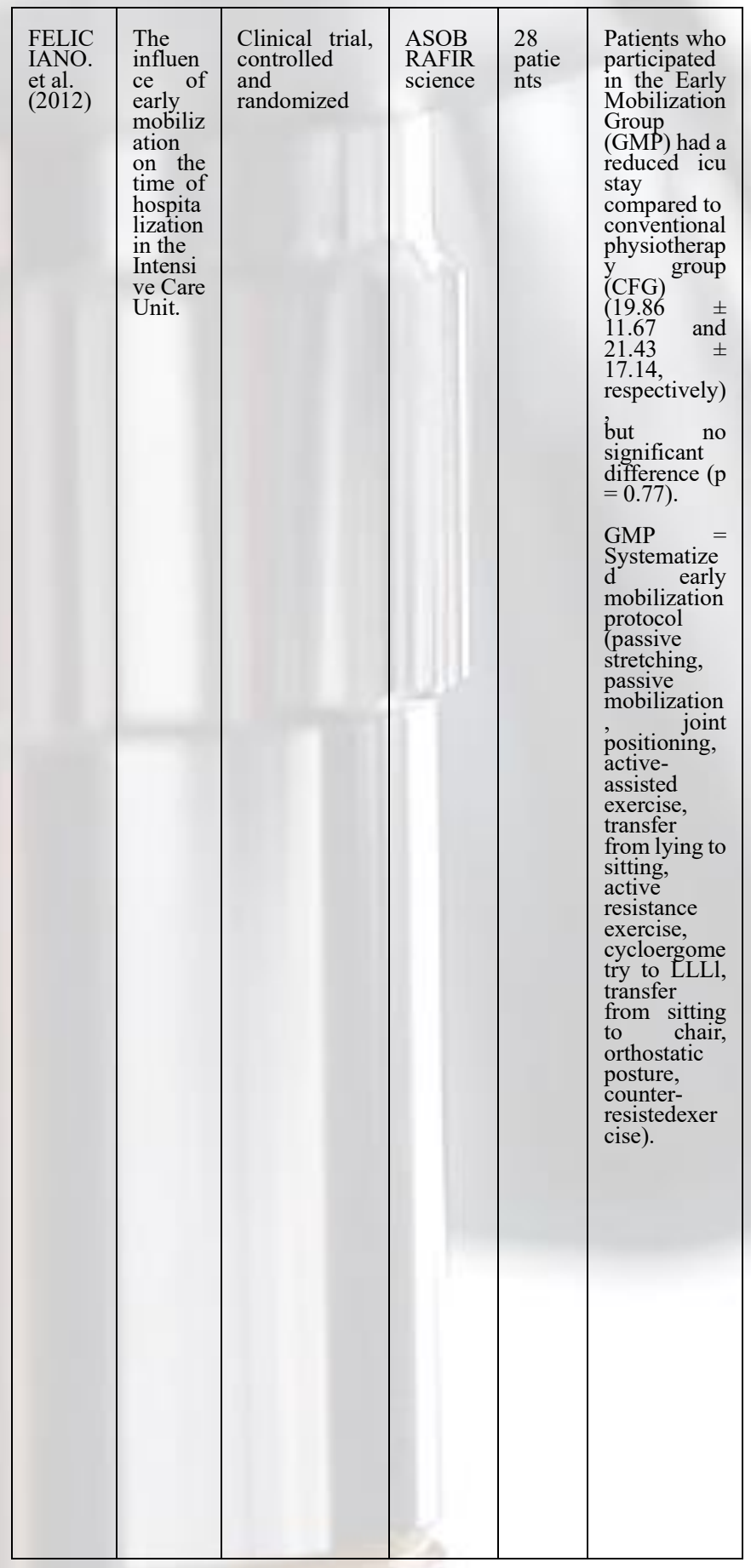

Table 3. List of references that addressed the effects of early mobilization in reducing the time of hospitalization in critically ill patients in the intensive care unit, according to author, year, article title, study design, journal, sample size and results.

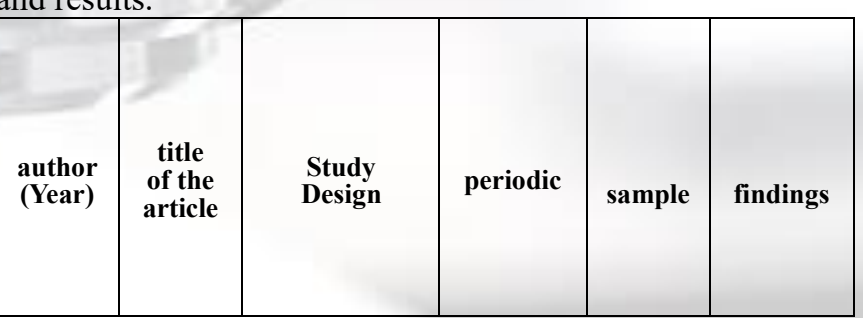


4 Ribeiro, M.H.S.; Monteiro, B.R.D.A; Melo, P.E.D.; Lacerda, S.D.L. Effects of early mobilization in reducing hospitalization time in critical patients in intensive care unit: an integrative literature review...

\begin{tabular}{|c|c|c|c|c|c|c|c|c|c|c|c|}
\hline $\begin{array}{l}\text { axe. } \\
\text { et al. } \\
\text { (2017) }\end{array}$ & $\begin{array}{l}\text { Effect } \\
\text { of } \\
\text { passive } \\
\text { exercis } \\
\text { e in } \\
\text { cycle } \\
\text { ergome } \\
\text { ter on } \\
\text { muscle } \\
\text { strengt } \\
\text { h, } \\
\text { mecha } \\
\text { nical } \\
\text { ventilat } \\
\text { ion } \\
\text { time } \\
\text { and } \\
\text { hospita } \\
\text { lization } \\
\text { in } \\
\text { criticall } \\
\text { y ill } \\
\text { patient } \\
\text { s: } \\
\text { random } \\
\text { ized } \\
\text { clinical } \\
\text { trial. }\end{array}$ & $\begin{array}{l}\text { Clinical trial } \\
\text { Randomized }\end{array}$ & $\begin{array}{l}\text { Brazilian } \\
\text { Journal } \\
\text { of } \\
\text { Pulmonol } \\
\text { ogy }\end{array}$ & $\begin{array}{l}38 \\
\text { patient } \\
\text { s }\end{array}$ & $\begin{array}{l}\text { No } \\
\text { significa } \\
\text { nt } \\
\text { differenc } \\
\text { es were } \\
\text { observed } \\
\text { between } \\
\text { the } \\
\text { Control } \\
\text { (CG) and } \\
\text { Intervent } \\
\text { ion (GI) } \\
\text { groups } \\
\text { regardin } \\
\text { g icu stay } \\
\text { (p }= \\
0.824) \text {. } \\
\text { GI= } \\
\text { Conventi } \\
\text { onal } \\
\text { Physioth } \\
\text { erapy + } \\
\text { use of the } \\
\text { lower } \\
\text { limbs } \\
\text { cycle } \\
\text { ergomete } \\
\text { r. }\end{array}$ & $\begin{array}{l}\text { Lai. } \\
\text { et al. } \\
\text { (2017) }\end{array}$ & $\begin{array}{l}\text { Early } \\
\text { Mobilizati } \\
\text { on } \\
\text { Reduces } \\
\text { Duration } \\
\text { of } \\
\text { Mechanic } \\
\text { al } \\
\text { Ventilatio } \\
n \text { and } \\
\text { Intensive } \\
\text { Care Unit } \\
\text { Stay in in } \\
\text { Patients } \\
\text { With } \\
\text { Acute } \\
\text { Respirator } \\
\text { y Failure. } \\
\text { ( Early } \\
\text { Mobilizati } \\
\text { on } \\
\text { Reduces } \\
\text { The } \\
\text { Duration } \\
\text { of } \\
\text { Mechanic } \\
\text { al } \\
\text { Ventilatio } \\
\text { n } \\
\text { and Stay in } \\
\text { intensive } \\
\text { care unit in } \\
\text { patients } \\
\text { acute } \\
\text { respiratory } \\
\text { failure). }\end{array}$ & $\begin{array}{l}\text { Retrospect } \\
\text { ive } \\
\text { observatio } \\
\text { nal study }\end{array}$ & $\begin{array}{l}\text { Archives of } \\
\text { Physical } \\
\text { Medicine } \\
\text { and } \\
\text { Rehabilitati } \\
\text { on }\end{array}$ & $\begin{array}{l}153 \\
\text { patien } \\
\text { ts }\end{array}$ & $\begin{array}{l}\text { Patients } \\
\text { after the } \\
\text { mobilizati } \\
\text { on } \\
\text { protocol } \\
\text { (GMP) had } \\
\text { a reduced } \\
\text { length of } \\
\text { stay in the } \\
\text { ICU } \\
\text { compared } \\
\text { to } \\
\text { before the } \\
\text { mobilisati } \\
\text { on } \\
\text { protocol. } \\
\text { (6.9d vs } \\
9.9 \mathrm{~d} \text {; P= } \\
.001) \text {. } \\
\text { GMP }= \\
\text { Early } \\
\text { mobilizati } \\
\text { on } \\
\text { protocol } \\
\text { according } \\
\text { to the level } \\
\text { of consciousn } \\
\text { conscion } \\
\text { ess of each } \\
\text { patient. } \\
\text { (Passive } \\
\text { mobilizati } \\
\text { on of the } \\
\text { extremities } \\
\text { mobilizati } \\
\text { on of } \\
\text { extremities } \\
\text { position on } \\
\text { the } \\
\text { bed,and } \\
\text { moving } \\
\text { from the } \\
\text { bed to a } \\
\text { chair next } \\
\text { to the bed). }\end{array}$ \\
\hline
\end{tabular}

Table 4. List of references that addressed the effects of early mobilization in reducing the time of hospitalization in critically ill patients in the intensive care unit, according to author, year, article title, study design, journal, sample size and results.

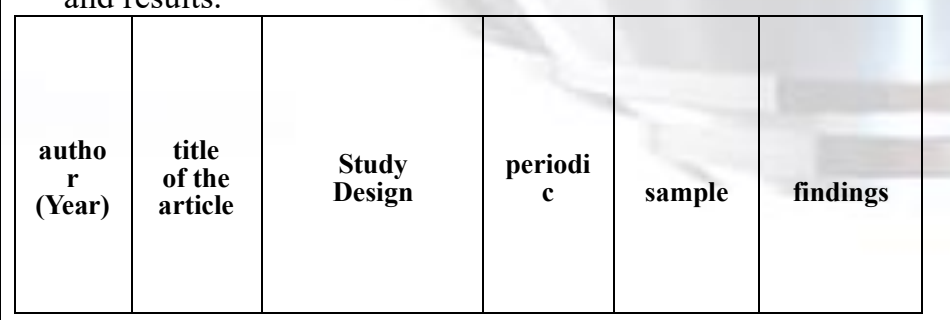

Table 5. List of references that addressed the effects of early mobilization in reducing the time of hospitalization in critically ill patients in the intensive care unit, according to author, year, article title, study design, journal, sample size and results.

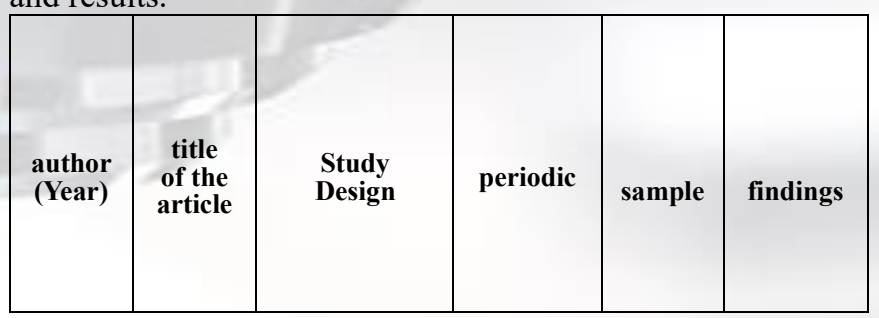




\begin{tabular}{|c|c|c|c|c|c|}
\hline $\begin{array}{l}\text { Moy } \\
\text { er, i... } \\
\text { et al. } \\
\text { (201 } \\
7)\end{array}$ & $\begin{array}{l}\text { Impleme } \\
\text { ntation of } \\
\text { an Early } \\
\text { Mobility } \\
\text { Pathway } \\
\text { in } \\
\text { Neurointe } \\
\text { nsive } \\
\text { Care Unit } \\
\text { Patients } \\
\text { With } \\
\text { External } \\
\text { Ventricul } \\
\text { ar } \\
\text { Devices } \\
\text { (Impleme } \\
\text { ntation of } \\
\text { an early } \\
\text { mobility } \\
\text { pathway } \\
\text { in } \\
\text { patients } \\
\text { with } \\
\text { external } \\
\text { ventricula } \\
\text { r devices } \\
\text { in } \\
\text { neurointe } \\
\text { nsive care } \\
\text { units) }\end{array}$ & $\begin{array}{l}\text { Formal } \\
\text { algorithm }\end{array}$ & $\begin{array}{l}\text { Journal of } \\
\text { Neurosci } \\
\text { ence } \\
\text { Nursing }\end{array}$ & $\begin{array}{l}45 \\
\text { patien } \\
\text { ts }\end{array}$ & $\begin{array}{l}\text { Early } \\
\text { mobilizati } \\
\text { on was } \\
\text { associated } \\
\text { with the } \\
\text { discharge } \\
\text { of more } \\
\text { than } 30 \% \\
\text { of patients } \\
\text { after the } \\
\text { beginning } \\
\text { of the } \\
\text { mobility } \\
\text { protocol. } \\
\text { The mean } \\
\text { length of } \\
\text { stay in the } \\
\text { ICU and } \\
\text { the mean } \\
\text { length of } \\
\text { stay in the } \\
\text { hospital } \\
\text { were not } \\
\text { significant } \\
\text { ly } \\
\text { different } \\
\text { between } \\
\text { the } \\
\text { interventio } \\
\text { n (G) } \\
\text { (18.2) x } \\
\text { control } \\
\text { (CG) } \\
\text { (20.7) } \\
\text { P=.262gro } \\
\text { ups. } \\
\\
\text { GI= } \\
\text { proper } \\
\text { positionin } \\
\text { g, sit by } \\
\text { the } \\
\text { bedside. } \\
\text { GC= } \\
\text { Absolute } \\
\text { rest. }\end{array}$ \\
\hline
\end{tabular}

Table 6. List of references that addressed the effects of early mobilization in reducing the time of hospitalization in critically ill patients in the intensive care unit, according to author, year, article title, study design, journal, sample size and results.

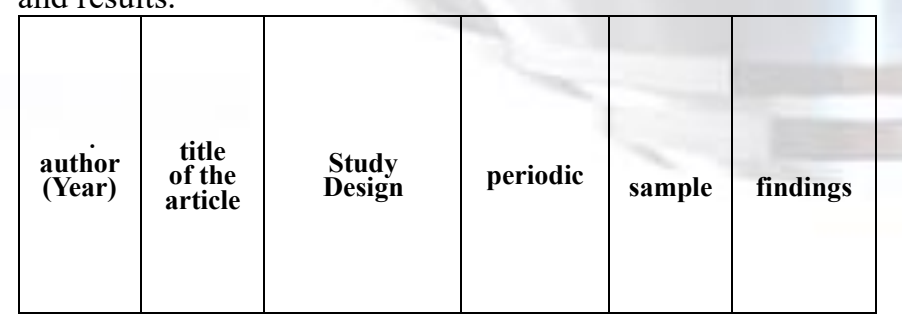

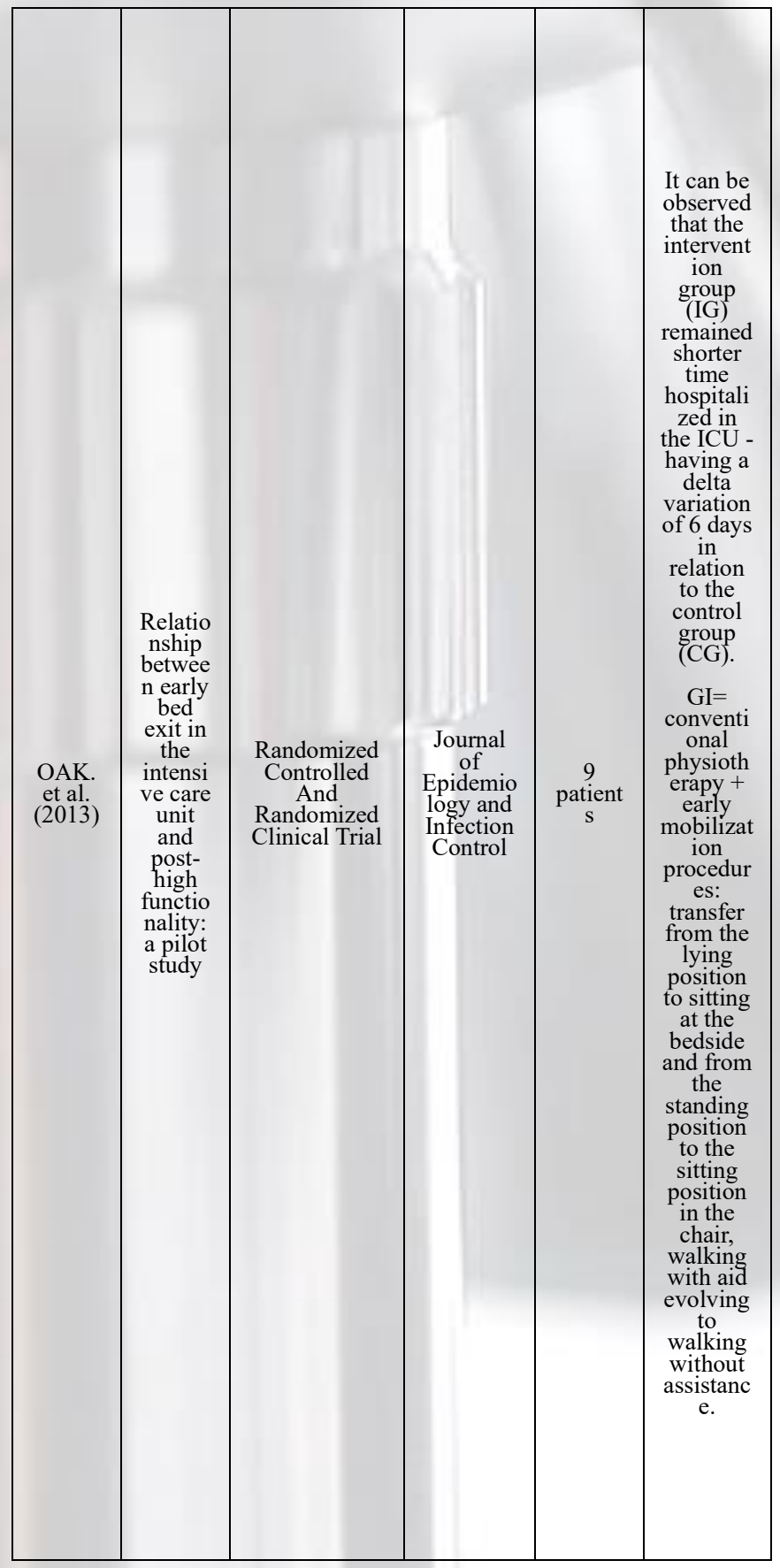

Source: Search Data

Santos et al., (2015), in a descriptive study analyzed medical records of 756 patients, it was observed with the application of variables with the cycle ergometer and orthostates the reduction of up to 5 days of hospitalization of patients, while other variables such as sitting at the edge of the bed / armchair increased the hospitalization time.

Feliciano et al., (2012), conducted a randomized controlled clinical trial in which 28 patients were analyzed, the patients of the mobilization protocol were a shorter time in the ICU compared to those who did not enter the mobilization protocol (19.86 \pm 11.67 and $21.43 \pm 17.14$, respectively), but without significant difference $(p=0.77)$. The patients who 
participated in the mobilization protocol performed activities such as: passive stretching, passive mobilization, joint positioning, active-assisted exercise, transfer from lying to sitting, active exercise resisted, cycloergometry to LLLl, transfer from sitting to chair, orthostatic posture and counter-resisted exercise, in a systematized way, depending on the level of consciousness of each patient. Patients who did not enter the mobilization protocol, i.e., the conventional physiotherapy group, performed only passive mobilization in the four limbs.

Machado et al (2017) conducted a randomized clinical trial in which 38 patients were analyzed, without finding significant differences between the Control and Intervention groups regarding the time of icu stay $(p=0.824)$. The Control group (GP) was submitted to conventional physiotherapy, including vibro compression maneuvers, hyperinflation by mechanical ventilator and tracheal aspiration, motor exercises of upper and lower limbs, passive and active assisted. The Intervention group (IG) in addition to conventional physiotherapy, used the lower limbs cycle ergometer.

According to Silva et al., (2014), early mobilization in the ICU seems to minimize functional losses, preventing and treating neuromuscular disorders resulting from longer patient survival and prolonged bed stay. Its use in clinical practice seems to be feasible and safe, being able to promote improvement in functional capacity, quality of life, in addition to reduction of hospitalization time and mechanical ventilation.

Lai et al., (2017), conducted a retrospective observational study in which 153 patients were included. Patients after the mobilization protocol had a reduced length of stay in the ICU compared to the period prior to the mobilization protocol. (6.9d vs $9.9 \mathrm{~d} ; \mathrm{P}=.001$ ). The mobilization protocol had interventions such as: passive obilization of the extremities, active mobilization of extremities, sitting position on the bed,and moving from the bed to a chair next to the bed.

Moyer et al., (2017), reported that early mobilization was associated with the discharge of more than $30 \%$ of patients after the beginning of the mobility protocol. The mean length of stay in the ICU and the mean length of stay in the hospital were not significantly different between the groups.

Carvalho et al., (2013), found that patients submitted to an early mobilization protocol by a team of physical therapists had a better rate of functionality after discharge from the ICU, shorter hospital stay in this unit and also shorter hospital stay. It is important to point out that the small sample size does not allow us many stratifications, so it is necessary to continue this research with larger populations for adequate inferences.

According to Mussalem et al., (2014) there are few reports in the literature about the performance of a multidisciplinary team, especially the physical therapist's work, regarding the improvement of patients in the unit, through an early mobilization protocol, with good internal validation and methodological quality evaluated by the PEDro scale. However, it was verified that early kinesiotherapy could minimize the loss of functional skills and, thus, reduce the hospital stay.

According to Moreira et al., (2020), early mobilization generated a positive impact on the hemodynamic and respiratory variables of patients, also promoted peripheral muscle strength gain significantly, thus boosting the recovery of patients, benefiting them physically. It can also be confirmed the reduction in the time of mechanical ventilation and hospitalization in the ICU and hospital, but without significant differences.

According to Pinheiro, Christofoletti (2012), the most used variations in critically ill patients were electrostimulation, cycle ergometer and motor kinesiotherapy techniques, all of which showed positive responses in critically ill patients. The level of evidence currently available about the impact of motor physiotherapy on length of stay in the intensive care unit and mortality is still low and further studies are needed.

According to Feitoza et al., (2014), studies have confirmed the efficacy of early mobilization in ICU patients, reducing hospitalization time, improving patient functionality and generating lower hospital costs. Given the complexity of the subject, further studies are needed to determine early mobilization protocols in order to avoid functional limitations in specific patients.

Pissolate, Fleck (2018), through a review, affirm that the studies demonstrate a beneficial response with regard to early mobilization, such as the improvement in respiratory and peripheral muscle strength, but further studies are still needed regarding the length of stay in the intensive care unit and mechanical ventilation due to the low number of patients and the low scientific evidence of the reviewed articles.

According to Aquim et al., (2018) early mobilization to reduce icu length showed mixed results, studies show improvement in functionality at the time of ICU and hospital discharge, but the proposed intervention does not significantly interfere in the length of stayof patients in the ICU andhospital.

According to Ferreira et al., (2016) benefits such as reduced hospitalization time and improved functionality were evidenced, generated by early mobilization in ICU patients. The most used interventions in Hospitals in Brazil were: the use of the cycle ergometer and passive and active mobilizations.

Brito et al., (2015) through a review report that early mobilization can anticipate recovery, reduce the incidence of pulmonary complications, decrease the time of mechanical ventilation (MV) and the time of hospitalization. They claim to be a viable, safe method and does not increase hospital costs.

According to Holstein, Castro (2019) studies in general indicated that early mobilization should be initiated even with the patient in a coma or seed and that it should progress according to the functional evolution of each of them. The use of early mobilization protocols also leads to a reduction in hospital costs since patients mobilized early have less hospital stay than those who weren't.

Santos et al., (2021) through a literary review report that all management performed by the physiotherapist must be understood and studied for the valorization of physiotherapy practices in the ICU, benefiting patients who depend on it. 


\section{Conclusions}

Through this study it was observed that early mobilization benefits critical patients in ICUs, generating quality of life and minimizing the deleterious effects of immobility. There was a decrease in the time of hospitalization of critically ill patients submitted to early intervention in the ICU, however, no significant differences were found between the groups in most of the studies found. Further studies are needed to expand the evidence regarding the theme addressed.

\section{References}

[1] AQUIM, E. E et al., Brazilian Guidelines for Early Mobilization in intensive care units. Brazilian Journal of Intensive Care. Sao Paulo. v. 31, n. 4, p. 434-443, 2019.

[2] BRITO, M.C. S et al., Early Mobilization in Adult Patients Submitted to Mechanical Ventilation (MV) in the Intensive Care Unit (ICU). Electronic Journal Updates Health. saviour. v. 2, n.2, p. 112-124, 2015.

[3] CARVALHO, T. G et al., Relationship between early bed exit in the intensive care unit and post-discharge functionality: a pilot study. Journal of Epidemiology and InfectionControl. Rio Grande do Sul. v. 3, n. 3, p. 82-86, 2013.

[4] CAVAlCANTE, E. A. F. P et al., Repercussions of passive mobilization in hemodynamic variables in patients under mechanical ventilation. Journal of Health \& Biological Sciences. Ceará, Ceará. v. 6, n. 2, p. 165-169, 2018.

[5] FEITOZA, C. L et al., Efficacy of motor physiotherapy in intensive care units, with emphasis on early mobilization. Electronic Journal Health \& Science. Sao Paulo. v. 5, n. 1, p. 19-27, 2014

[6] FELICIANO, V. A et al., The influence of early mobilization on the time of hospitalization in the Intensive Care Unit. SCIENCE ASSOBRAFIR. v. 3, n. 2, p. 31-42, 2012.

[7] FERREIRA, K. S, et al., Early Mobilization in Patients Hospitalized in the Brazilian Intensive Care Unit: A Literature Review. saviour. 2016.

[8] FONSECA, D. P et al., Impact of ambulation associated with early mobilization in critically ill patients: systematic review. ConScientiae Health. Paraná, Paraná. v. 15, n. 2, p. 325335, 2016.

[9] HOLSTEIN, J.M; CASTRO, A.A.M. Benefits and Methods of Early ICU Mobilization: A Systematic Review. LifeStyle Journal. Sao Paulo. v. 6, n. 2, p. 07-22, 2019.

[10] LAI, C et al., Early Mobilization Reduces Duration of Mechanical Ventilation and Intensive Care Unit Stay in Patients With Acute Respiratory Failure. Archives of Physical Medicine and Rehabilitation. Taiwan. v. 98, n. 5, p. 931-939, 2017.

[11] MACHADO, A. S et al., Effect of passive exercise in cycle ergometer on muscle strength, mechanical ventilation time and hospitalization in critically ill patients: randomized clinical trial. Brazilian Journal of Pulmonology. Rio Grande do Sul. v. 43, n. 2, p. 134-139, 2017.

[12] MOREIRA, M, A et al., Effects of Early Mobilization in Patients Hospitalized in intensive care unit: Systematic Review. Health Themes. João Pessoa. v. 20, n. 1, p. 117-139, 2020.
[13] MOYER, $M$ et al., Implementation of an Early Mobility Pathway in Neurointensive Care Unit Patients With External Ventricular Devices. Journal of Neuroscience Nursing. Philadelphia, Philadelphia. v. 49, n. 2, p. 102-107, 2017.

[14] MUSSALEM, M, A, M et al., Influence of early mobilization on peripheral muscle strength in patients in the Coronary Unit. SCIENCE ASSOBRAFIR. reef. v. 5, n. 1, p. 77$88,2014$.

[15] PINHEIRO, A. R; CHRISTOFOLETTI, G. Motor physiotherapy in patients admitted to the intensive care unit: a systematic review. Brazilian Journal of Intensive Care. Mato Grosso do Sul. v. 24, n. 2, p. 188-196, 2012.

[16] PIRES-NETO, R.C et al., Early Mobilization Practice in a Single Brazilian Intensive Care Unit. Journal of Critical Care. Sao Paulo. v. 30, n. 5, p. 896-900, 2015.

[17] PISSOLATO, J.S; FLECK, C.S. Early mobilization in the adult intensive care unit. Physiotherapy Brazil. Rio Grande do Sul. v. 19, n. 3, p. 377-384, 2018.

[18] SANTOS, A.C et al., REPERCURSSIONAND BENEFITS OF EARLY MOBILIZATION IN CRITICAL PATIENTS RESTRICTED TO THE BED. JRG Journal of Academic Studies. Goias. v. 4, n. 8, p. 59-66, 2021.

[19] SANTOS, F et al., Relationship between Early Mobilization and Hospitalization Time in an Intensive Care Unit. Electronic Magazine Management \& Health. Santa Catarina. v. 6, n. 2, p. 1394-1407, 2015.

[20] SCHUJMANN, D. S et al., Progressive mobility program and technology to increase the level of physical activity and its benefits in respiratory, muscular system, and functionality of ICU patients: study protocol for a randomized controlled trial. Trials. Sao Paulo. v. 19, n. 1, p. 274, 2018.

[21] SILVA, V. S et al., Mobilization in the Intensive Care Unit: a systematic review. Physiotherapy andResearch. saviour. v. 21, n. 4, p. 398-404, 2014. 